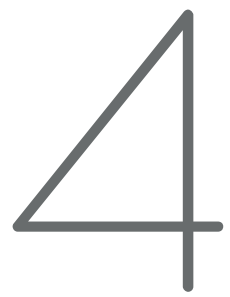

\title{
HERNÁN MALO, UNA ÉPOCA
}

\author{
José Valencia
}


Antes que Hernán Malo y después de Hernán Malo, la historia de la Pontificia Universidad Católica del Ecuador ha quedado signada por su paso; y es que Hernán Malo no fue "tan sólo" el hombre: un ser conflictivo en una época de arduas jornadas. Su sombra abarcó y alumbró un proceso, una era, una estación en la vida de esta Alma Mater.

No me toca a mí referirme al Hernán Malo que coleccionaba miedos, bailaba con las notas de Vivaldi y prometía por teléfono tres cuestiones ..... que a la final siempre resultaban ser dos. Hoy ese hombre nos ha dejado un silencio, pero un silencio poblado de luces.

Hablaré, al decir Hernán Malo, de aquello que lo une "impersonalmente" con estas paredes: su paso por la Universidad Católica y las realizaciones que ayudó a moldear con sus manos. Hablaré de la obra que alumbró, donde su espíritu aún habita, ella sobrevive a las turbias intrigas, a los grisáceos móviles y a las fanáticas incomprensiones.

Hernán Malo ya es una época y quienes hacemos desde distintas funciones la Universidad Católica, reclamamos a esa formidable era como nuestra.

Las raíces de la etapa de Hernán Malo se remontan a la esencia misma de la universidad ecuatoriana, en general, y de la Universidad Católica, en particular. La universidad ecuatoriana, fiel reflejo de una sociedad donde jamás llegó a imponerse hegemónicamente fuerza social alguna, se atascó al igual que aquella, en conflictos de largo aliento, sin definiciones y con espesas disquisiciones, donde a la postre sólo sacaron provecho quienes se interesaban en distraer la atención universitaria de la verdadera lucha.

La universidad ecuatoriana tiene entre sus hijas a la Universidad Católica, pero la vinculación "de sangre" con otros centros de educación superior no hace, definitivamente, de la Católica, una universidad que haya afrontado problemáticas similares a las de sus hermanas. Juega un decisivo papel en esta desemejanza, el objetivo e idea que inspiraron su creación, principios que tienen una correspondencia y relación de causalidad con el momento histórico ecuatoriano en que la Universidad Católica vio la luz. 
Una época conflictiva contempló el nacimiento de esta Universidad: todavía resonaban en las mentes aquellas ilusorias jornadas de la Gloriosa; la FEUE se organizaba con sorprendente vigor a la par que la Iglesia contemplaba el agotamiento de su mensaje entre la intelectualidad; el pensamiento universitario acogía vehementemente nuevas interpretaciones de la realidad nacional.

La Gloriosa, que puso en retirada el fariseísmo liberal, fue lamentablemente usufructuada por las fuerzas tradicionales, en una serie de manejos aún confusos para nuestra historiografía.

No es pues, una mera coincidencia que la Universidad Católica fuese fundada allá en el año 46.

La clase dominante tradicional, especialmente afincada en la Sierra, comprendió con su experiencia del enfrentamiento al laicismo, que para asegurar un lugar dentro del espectro ideológico nacional debía ocupar -firmemente- un lugar en el aparato reproductor de la ideología: la universidad. Naturalmente que la Universidad Católica debió nacer unida a la Iglesia, única fuerza organizada capaz de hacerse cargo de tal empresa.

Por su lado, la institución eclesial, conmovida como estaba por la pronunciada secularización de la universidad ecuatoriana, buscaba difundir su mensaje en el campo de la juventud profesional.

No procedía su lucha en el seno de la universidad laica, donde el discurso religioso no encontraba campo propicio para echar raí- ces, fenómeno que no cabe analizar este momento. La alternativa emprendida fue la creación de un centro educativo regido por la Iglesia, encomendado a la Compañía de Jesús, congregación ésta la más idónea para tal labor en consideración a los altos exponentes del pensamiento cristiano que siempre se ha preciado de poseer dentro de su seno.

La Católica de ese entonces fue -en mi criterio- la respuesta ideológico-religiosa del tradicionalismo a una realidad social que parecía "írsele de las manos". Y la Universidad cumplió fielmente su misión: a más de engendrar profesionales ligados a su pensamiento, entregó un conjunto de organismos de inspiración religiosa, que en su proyección social incursionaron con posiciones políticas que eran de esperarse. Estas pautas de acción no fueron soterradas, eran la meta perseguida y sinceramente expresada por su fundador, por lo menos en cuanto se refiere a sus principios. 
Mas, como es una evidente realidad, los tiempos tienen varias estaciones y la fuerza motora del cambio apareció precisamente en la Iglesia, si bien no hay que desconocer la influencia de una nueva corriente de pensamiento social en América Latina en la modificación de las posiciones tradicionales de la organización religiosa. La Iglesia tomaría formalmente una posición apolítica, entendiéndose como apolítica al desligamiento material de formaciones partidistas específicas, lo que no necesariamente significó un alejamiento de su raíz ideológica.

Cuando Juan XXIII abrió los claustros del pensamiento religioso a vientos frescos, insufló savia nueva a la tradicionalista Iglesia Latinoamericana, que en Medellín aplicaría las enseñanzas del Vaticano II a su realidad concreta.

Es a mediados de los sesenta cuando las tradicionalistas estructuras de la Universidad Católica empiezan a conmoverse ante la arremetida de los vientos nuevos. Salvar lo bueno y positivo que había en ellas, y además, presentar una fresca respuesta que abra ambiciosos horizontes para la institución, eran no sólo acuciantes necesidades sino por la situación propia de la Universidad Católica- un verdadero reto.

Hernán Malo, con su intervención en la vida de este Universidad, asumió esa necesidad y ese reto bajo las ineludibles fronteras que caracterizan al obrar humano, limitaciones que quedan relegadas ante la formidable irrupción de una gestión trascendente.

Pero ¿cómo influyó el cambio de rumbo en la orientación religiosa para la reformulación del proyecto de la Universidad Católica? Quizá por recurrir a ejemplos extremos como ilustración de la evolución del compromiso cristiano en la Iglesia Latinoamericana se ha creído ordinariamente que el nuevo discurso eclesial originó -únicamente- una corriente radical. No es así, aparecieron en realidad posiciones diversas, que van desde el utópico idealismo voluntarista hasta el más desembozado programa reaccionario.

A mi modesto entender, los grandes logros de la época de Hernán Malo buscaron una necesaria reforma de la institución frente a la diferente sociedad de entonces, diferente en razón de las profundas variaciones que sufriera su ser. No llegó ciertamente, por las específicas circunstancias que lo rodearon, a incursionar frontalmente en el radical campo de la Teología liberadora. 
Hernán Malo entendió las exigencias de los inéditos tiempos que se presentaban y contempló que el cimiento de una reforma debería partir, necesariamente, del orden académico: de la estructura misma de la universidad y de su visión de la sociedad ecuatoriana. Visión que lleva a una institución académica a elaborar la opción que ofrecerá al grupo humano al cual se debe.

Las realizaciones de la época de Hernán Malo podrían ser motivo de largas y profundas reflexiones, bástenos enunciar la tolerancia política, el pluralismo ideológico y la libertad de cátedra. Premisas estas que indirectamente coadyuvaron al resurgimiento del movimiento estudiantil, que entró a cumplir el papel que le está destinado como integrante de una comunidad universitaria, llevando así a una práctica real -no ilusoria ni prestidigitadora- las enseñanzas de Córdova.

Pero además, otros sectores de la Universidad alcanzaron con Hernán Malo su materialización orgánica: las asociaciones de profesores y empleados. Pasándose así a completar la familia universitaria de la Católica.

La Universidad Católica, aceptando los ricos postulados humanistas del catolicismo, es ante todo una universidad ecuatoriana y por tanto mal puede sustraerse de los espacios logrados en las largas luchas de la universidad latinoamericana.

Continuando con la enunciación de los aspectos más sobresalientes del rectorado de Hernán Malo, me referiré a la que tal vez es una de sus más fecundas actuaciones: hasta entonces, el carácter privado y oneroso de la Universidad Católica la convirtió en paso obligado de los alumnos educados en colegios particulares con medios económicos, divorciándose así -al menos en cuanto se refiere a la educación impartida en las principales Facultades- de su profundo compromiso católico, tan radicalmente antielitista. A este respecto, son dignas de recordar las palabras del Padre Ellacuría cuando afirmaba que: (los valores cristianos de una universidad) "no son cuestión de intenciones; son cuestión de realidades verificables. Si no procede en su actividad desde la determinación de nuestro mundo histórico como pecado institucional, ignora la base real de la historia de salvación; si no combate contra el mal estructural, no está en la línea del Evangelio. El cristianismo de la universidad no debe 
medirse ni desde profesiones de fe; ni desde acatamientos jerárquicos, ni desde la enseñanza explícita de temas religiosos aunque sea muy necesario en muchos países un centro de reflexión y de producción teológica-, sino desde su concreta orientación histórica: a qué señor sirve, sabiendo muy convencidamente que no se puede servir a dos señores, y a uno de los señores a los que no se puede servir es a la riqueza, entendida como un dios opuesto al Dios que se reveló en Cristo".

La obra de Hernán Malo entendió que la anacrónica patología elitista debía ser anulada de nuestra universidad, su contribución hacia el establecimiento de la pensión diferenciada sería de por sí, razón suficiente para contar al padre Malo como derogador de trasnochadas aspiraciones.

Sería largo precisar otros importantes rasgos de la actuación de Hernán Malo: su apoyo a la creación de la Facultad de Ciencias Humanas con el Departamento de Antropología, la implementación de la Oficina de Planificación Académica, Bienestar Universitario, el sistema de estudios mediante créditos, son parte de una lista casi inagotable.

Toda esa fecunda labor se vio detenida por los poderosos intereses que conspiraron junto con las limitaciones humanas de rigor. Las fuerzas ceden hasta cierto punto, y si son aún vitales no se quiebran, se vuelven violentas y ciegas. Todo buscan destruir.

La misma actividad y dinamismo de Hernán Malo lo envolvieron en una vorágine de la que no podría salir, lo distrajeron de la labor de zapa que emprendieron quienes lo combatieron.

Una cruda batalla decidiría finalmente el destino de Hernán Malo, atacaría su obra e iniciaría un prolongado período de contrarreforma. Todavía sentimos la falta de unos estatutos universitarios que recojan sus postulados de avanzada.

Sin embargo, fundamentales conquistas de su período han calado profundamente en la conciencia de la Universidad Católica y han pasado a constituirse en realidades por las que siempre lucharemos.

Hernán Malo se ha ido ¡Cuánto nos dice esto del pasado! Y ¡cómo nos recuerda las tareas que aún restan por cumplirse! 
